\title{
Millennial vs Non-Millennial Teachers: Understanding the Ongoing Battle Occurring in Classrooms Around the World
}

\author{
Eric Roberts \\ Keiser University
}

The purpose of this multicase study is to understand the millennial teachers' perceptions of challenges in secondary-schools and to explore their views and beliefs on how non-Millennial educational leaders influence these challenges. A sample of 15 millennial secondary educators was interviewed to explore their perceptions of various challenges and opportunities. Transcribed interview data were coded as patterns and themes were identified. The findings from this study revealed millennial secondary education teachers pay close attention to how their relationships with non-millennial leaders impact their professional development and indicated that an environment supportive of professional growth is their utmost desire.

Keywords: Millennials, Secondary-School, Millennial, Generation, Non-Millennial, Administrators, Perceptions, Teachers, Educators, Leadership, Professional, Growth, Barriers, Opportunities

\section{INTRODUCTION}

When millennials entered the workforce a high level of excitement and expectation occurred that energized many members of the older generations, but the perception of the younger generation has since changed. Successful leaders have an inherent awareness of clashes between leaders and young employees (Reuteman, 2015). In the 21st century workforce, members of the millennial generation face various challenges. Communication barriers with non-millennials and obtaining professional growth are among the top issues the millennial generation may encounter in today's workplace. Many millennials lack the understanding needed to be productive and supporting parts of a workforce (Carbaugh, 2016). Often, unrealistic expectations by millennials can influence employee relations negatively (Lerner, 2015). Teachers who are members of the Millennial generation believe their secondary-school employers must place their careers and their relationships with their leaders as a priority (Layton, 2016). This often causes rifts in communication and challenges with setting expectations. The unrealistic expectations that secondary-school Millennial teachers possess is evident in modern society. Millennials enter a secondary school organization expecting to be given the attention that older teachers believe should be earned.

Millennials are being acknowledged as the future leaders of secondary-schools (Emeagwali, 2011). Organizational administrators must create cultures that incorporate the strengths of millennials in a way that allows them to be a part of the overall growth and planning. Leaders in secondary schools are working continuously to improve processes and strategies (Dolph, 2016) to accomplish this goal. As continued progress is sought, the demographics of many secondary-schools is changing based on a more 
global and mobile workforce (Hickey, 2016). Millennial and non-Millennial leaders in a secondary-school environment must be receptive to the cultural and generational differences that exist within their organizations to develop a sense of teamwork and belonging among members of the various generations (Jones-Goods, 2015). Employers in secondary-schools are looking for teachers who can operate with a rigid lesson plan format (Gafoor \& Umer Farooque, 2010). The specific problem is that millennials need a better understanding of the variations in generational thinking toward working in a secondary-school organization to increase their chances for success at their respective places of employment.

Millennials have high expectations regarding the development of their careers (De Hauw, \& De Vos, 2010). Entering a secondary-school workplace with the expectations and beliefs about what an organization will provide may have a negative influence on employees if the expectation does not match the actual culture. Members of the millennial generation strongly believe that employers should be proactive to ensure they are personally and professionally empowered, while also assisting millennials with finding boundaryless opportunities in their professions (Severson, 2015). Entering a secondaryschool organization with expectations that company leaders will provide assurances of professional success puts millennials in the position for immediate dissatisfaction. In every company, an alignment of worker expectations and work realities must occur (Brady, 2010). Workplace tensions are often caused by a millennials' false expectations of the existing work culture and expectations of organizational accommodation, which originate from how organizational leaders may have made themselves malleable to the needs and desires of the Millenials (Hershatter \& Epstein, 2010). The findings from the conclusion and recommendations of this study may be used to facilitate future research, while also enhancing preparation and productivity in the secondary-school environment.

\section{LITERATURE REVIEW}

This study was an exploration of the perceived challenges that millennials believe they may face in a secondary-school working environment. Challenges are typically defined as obstacles with a potentially adverse effect on an individual's successful start or foundation in the workforce (Hogan, Kyaw-Myint, Harris, \& Denronden, 2012). Hossain and Terwelp (2015) asserted in the past four decades changes in the U.S. economy have had dramatic implications for the labor market fortunes of the millennial generation. Members of the millennial generation have a strong presence in the modern workforce, evidenced by the field of education, as the number of millennial teachers in secondary-school classrooms is increasing (Johnson, 2006). Having such a significant influence on the future, millennials are shaping U.S. society with their openness and abilities as independent thinkers.

To obtain a better understanding of the perceived challenges that millennials in a secondary-school organization encounter, the current study will include literature pertaining to the current trends of millennials in the workplace and the challenges they may face with non-millennials. The literature review will be used to provide information on the background of why certain characteristics and behaviors exist among millennials and the potential reasons why challenges may be perceived. Data will be presented on the societal influences and other factors that may cause the relationship between millennials and nonmillennials to be a success or failure.

\section{THE MILLENNIAL GENERATION AS TEACHERS}

As millennials enter the workforce, researchers have found it is becoming increasingly essential to ensure that non-millennials in a secondary-school workforce understand the millennial generation (Farrell \& Hurt, 2014). Current literature on millennial characteristics contains insight into why challenges in a secondary-school working environment may exist. In the current literature review, the specific characteristics of millennials are examined, followed by a discussion of peer-reviewed research findings from the current literature regarding workforce issues that might be used to explain the reason challenges may exist for millennials in secondary-school organizations. 
Millennial teachers are touted to be the most diverse generation to date (Hlavinka, 2014). The group of young educators is identified as the millennial generation or Generation Y, with birth years ranging from 1977 to 1995; the individuals have been identified as a group that is known to be different from prior generations (Smilansky, 2016). Scant literature exists specifically on millennial teachers, but the characteristics and behavior of the members of the generation are consistent throughout the workforce. During their study on millennials working in the field of education, Smith and Galbraith (2012) stated millennials can be challenging and non-millennials need to adjust. Millennials have developed a type of independence whereby they embrace society, becoming more open to many ideas that would not have been accepted otherwise (Smilansky, 2016). Based on millennials, ideas about diversity, openness to change, and a need for better communication are more often discussed within the secondary-school workplace.

\section{COMMON CHARACTERISTICS}

Three areas of millennial characteristics exist that influence the reason millennials may face challenges in secondary-school organizations, including: (a) expectation of accommodation, (b) diversity, and (c) influential factors of social media.

\section{Expectation of Accommodation}

One of the primary sources behind the creation of millennials' belief of privilege is the amount of unprecedented positive reinforcement and positive attention they receive. Also known as the "Trophy Kids," millennials have been given positive feedback throughout their lives; regardless of how poorly they performed (Soenens, Wuyts, Vansteenkiste, Mageau, \& Brenning, 2015). The positive feedback reinforcement for good or bad results was translated by members of the millennial generation into a constant understanding and belief that no matter what they did, it would be accepted and embraced. Twenge (2010) defined entitlement as expecting something in exchange for nothing. The entitlement mentality has resulted in creating many issues, challenges, and beliefs throughout the professional career of a millennial teacher. Rodriguez and Hallman (2013) stated that millennial teachers are distinctly unique from members of previous generations. Results of growing up in a culture that believed in "trophies for everyone", created an unquenchable thirst for praise and entitlement (Peebles, 2008). This study explores the idea of having such a mind-set of entitlement and discusses the types of challenges that millennials believe may arise in the secondary-school workforce. Responses to the interview questions will provide additional insight into resolving the differences in a better fashion between millennials and nonmillennials in a secondary-school environment.

\section{Diversity}

The largest generation to date, millennials are known to be the most diverse generation in American history (Ellis, 2016). It is important to consider the diversity in modern secondary-school organizations regarding millennial and non-millennial employees. Diversity is a vital factor in the discussion of perceived challenges educators face in secondary-school organizations. Millennials are often summarized by the following terms: socially conscious, creative, entitled, and engaging (DeVaney, 2015). The commonalities of millennials are societal strongholds and have often defined an entire generation of young educators. When people say the word, millennial, the core characteristics of the people being discussed include socially conscious, creative, entitled, and engaging. The development of the characteristics of millennial educators has created an educational culture that is engaged in diversity pedagogy, which is a set of principles pointing out the connection between a diverse background and cognition (Ragoonaden, Sivia, \& Baxan, 2015). The diversity of millennials has opened the field of education to a more opinionated and revealing set of attitudes. Cramer (2015) asserted more people are comfortable stating their opinions, standing firm to their true beliefs and feelings, and have a stronger sense of expressiveness. The conclusions found in this research were used to support that modern millennials are comfortable speaking their minds and looking for innovative ways to live personally and 
professionally. The various types of information and social advances have given millennials, who are in secondary-school organizations, the diversity and the tools to shape their minds and behaviors.

\section{Influential Factors of Social Media}

While all generational cohorts utilize social media, millennials are the most frequent users (Sago, 2010). The use of social media is common practice for the millennials in modern society. In research on social media in education, Burbeles (2016) stated society is where people live, share, and learn, so it is expected that millennial teachers would be influenced professionally. Influences, such as more political and professional awareness that come with involvement in social media can heavily influence the thought processes and behavior of millennial educators. Individuals in educational organizations have begun to make an extra effort toward strengthening their use of social media for millennials (Smith, 2012). Researchers have found certain groups of millennials who support movements with a strong agenda are conflicted based on a mingled sense of old frustration and new opportunity (Gass, 2015), which can also have an influence on how they perceive certain scenarios in their workplace. If such millennials are a part of a movement involving ethnicity, they may respond to a question regarding barriers they believe they may have faced with a racially motivated answer. In a study on job satisfaction, Campione (2014) found millennial employees are affected by the interplay of various social. Social media has become such an integrated aspect of education that most millennials are willing to merge their online presence and their daily interactions with their peers at their respective workplaces (Barry, Marzouk, Chulak-Oglu, Bennet, \& Tierney, 2016). If millennials are heavily influenced by social media, social media can also be used to influence how they perceive the various challenges they may face in the workplace. The influence of social media on millennials is the reason Black (2013) confirmed the strong influence of the millennial generation on many workforce regulation changes that have occurred, such as the use of cell phones, and why many controversial issues are in the forefront of modern media topics. The inundation of information has had a significant influence in the field of education. A current trend involves curriculum designers and educators implementing a variety of free social media tools into their organizations (Ganis, 2009). The many influential factors that millennial educators will encounter from social media can heavily influence their relationship with non-millennials.

\section{METHODOLOGY}

The current case study was used to focus on a specific group of individuals who were intrinsically bound by their experience and age. Case study methodology was suitable for the current study based on the parameters for each subject of interest. Researchers have proven that qualitative case study methodology is a sufficient tool used to study complex phenomena and can be used as a valuable tool to develop theory and interventions (Baxter \& Jack, 2008). The cases for the current research study were each millennial teacher discussing his/her perception of benefits and challenges they believed may exist in their field. Each millennial's case had the common foundation of working in a secondary-school institution and having worked for at least a 6-month period.

In the current study, the researcher interviewed 15 participants. Open-ended questions were used to allow for fluid and unconstrained responses from the participants. The objective was to explore the depth of the millennials' experiences and feelings about perceived benefits and challenges in a secondaryschool working environment. Checkley (2016) stated open-ended questions explore possibilities, clarify thinking, and produce evidence-based conclusions. Using the following open-ended questions allowed the researcher to delve further into any perceptions millennials may have of perceived challenges in a secondary-school environment.

\section{Interview Questions}

1. Explain the process you took to become employed with this organization?

2. What were the influences that caused you to accept this job? 
3. Prior to accepting the offer for this position, explain the challenges you felt may have been a concern, due to being a Millennial?

4. Prior to accepting the offer for this position, explain the benefits you felt may have been available, due to being a Millennial?

5. How long have you been working with the organization?

6. Describe your experience at the beginning of your employment in the secondary-school institution?

7. After you were employed in a secondary-school institution, explain whether or not you feel being a Millennial may have been a concern?

8. After you were employed in a secondary-school institution, explain whether or not benefits exist due to being a Millennial?

9. Please provide an explanation of how often you communicate with your non-Millennial leadership?

10. How comfortable are you with talking to your non-Millennial leadership?

11. What challenges do you believe exist, due to you having non-Millennial leadership?

12. What benefits do you believe exist, due to you having non-Millennial leadership?

13. Tell me about a time you may have faced a challenge because of your non-Millennial leadership and how did you view your leader due to those challenges?

14. Describe what you believe can be done to overcome this challenge?

15. Tell me a time you may have benefited due to your non-Millennial leadership and how did you view your leader due to those benefits?

16. Explain whether or not you believe age makes a difference in how a leader performs within your organization?

17. Explain how you believe your age will create future challenges in a secondary-school institution?

18. Explain how being a Millennial may provide future benefits in a secondary-school institution?

\section{ANALYSIS OF FINDINGS}

The findings of the current research study provided insight into the perception of millennial teachers' experience and how they perceived their non-millennial leaders based on the perceptions. The perceptions were consistent throughout the responses. The participants felt their leaders had the potential to mitigate or strengthen the barriers or challenges perceived to exist in a secondary-school organization. The results of the current study were consistent with current literature. It is essential that non-millennials in a secondary- school workforce understand the millennial generation (Farrell \& Hurt, 2014). As a result of age diversity, it is likely that employees will have varying approaches to how they perceive certain situations in the workplace (Hall, 2016). Identified themes found in this study were used to support the notion of the openness by millennial teachers in secondary-school organizations towards embracing a productive level of communication with their non-millennial leaders. Themes such as positive, rewarding, and informative indicated that millennial teachers seek a relationship based on being aware and apprised of their status and involvement in the workplace.

The finding was in line with the data from the current study, which indicated that millennials seek to obtain knowledge and feedback from their surroundings. Openness to feedback was a common characteristic of the millennial teachers in this study. Participants mentioned their willingness to accept positive and negative feedback for the betterment of their futures in their respective secondary-school organizations, while also expecting their non-millennial leaders to take the time to get to know them. The participants sought advice and were more receptive to criticism from the non-millennial leaders who took additional time to speak with them. Non-millennial leaders who were more open received a more positive response when providing professional advice to the millennial teachers.

The findings indicated definite benefits and challenges millennial teachers were able to identify and describe in detail. The level at which the participants explained the perceived benefits and challenges allowed for an understanding of the amount of thought they had concerning the culture in their respective 
place of employment. Several participants mentioned specific challenges and benefits they believed existed in their secondary-school organizations. Participants provided their opinions regarding how their non-millennial leader was viewed based on the perceptions.

The data in the current study indicated that participants' experiences in a secondary-school organization involved a positive outlook and understanding. The themes from the question generated responses leading to a discussion about positive environment, professionally rewarding, and informative. The themes were similar to the current literature in the sense of millennial teachers being heavily influenced by their surroundings. Millennials are the most frequent users of social media (Sago, 2010) and are constantly seeking to learn from their devices. The mindset was no different when placed in a secondary-school organization. The themes of learning and informative were indicators the participants were willing to learn and be taught by their non-millennial leaders. If the leaders in the secondary-school organization did not take the time to understand that millennials were open to learning, it could create a culture of unease and misunderstanding. Just as social media venues are places where people share and learn (Burbules, 2016), millennial teachers seek the same type of interaction in their respective places of employment.

\section{CONCLUSION}

The results of the current study provided evidence that was used to both support and refute the existing body of literature. Based on the personal experiences of millennial teachers in a secondary-school organization, implications exist for school leaders to take action towards creating a positive working culture. The findings are essential to research in the field of education. A clear variance existed between the communication of a millennial teacher and non-millennial leader within a secondary-school organization in South Florida. The millennial teachers possessed assumption of how non-millennial leaders should treat them. Therefore, school leaders may benefit from the findings of this study that indicate a need exists for an acknowledgement of structure and guidance for millennial teachers in a secondary-school organization. The study showed the actions of a non-millennial leader indicated a sense of comfort in the fact that millennials just need to "do their time" to earn the right to take action toward professional growth. Responses from the participants in the current study provided insight into the value of communication. Non-millennial leaders must take the time to analyze how they can better incorporate their millennial teachers into their long term plans. With these findings, individuals seeking to hire millennial teachers, such as teacher recruiters or leaders in a secondary-school, will be able to provide the millennials with a clear understanding of expectations and advise them on how professional growth may be obtained. It will also allow non-millennial leaders to possess a stronger sense of awareness towards certain behavior displayed by millennial teachers.

School leaders must consider addressing policy development for professional growth in a secondaryschool organization, based on the findings of this study. The implementation of programs such as peer mentorship, leadership, and growth plan may enhance the level of communication between nonmillennials and millennials in a secondary-school organization. These types of programs will assist school leaders with providing the necessary guidance and structure needed for millennial teachers to feel they are getting the necessary tools from their environment that gives them a sense of progression and growth. School leaders must create a culture of development and give millennial teachers the opportunity to learn about their profession and themselves.

The findings in the current study may be used to ensure millennial teachers in secondary-schools are able to better understand themselves and other teachers who are older, to ensure they possess a realistic perception of how they are viewed by their non-millennial leaders.

While the existing literature was used to support the findings in some areas, the data that was used to refute the current literature can be used to implement a better understanding of how to possibly guide a millennial away from the common unwanted behaviors. The findings showed that millennials seek to learn, grow, and educate themselves through interaction with their non-millennial leaders. Despite a perception that millennials behave in a self-centered and disrespectful manner, the findings of the current 
study showed that millennial teachers are very receptive to communicating and embracing their surroundings as an opportunity to enhance their careers. Based on the knowledge gained from the current study, an opportunity exists for non-millennials to have the ability to surpass the initial perceived negative behavior of millennials and embrace their deeper desire to learn and pursue gratification through employment.

\section{RECOMMENDATION FOR FUTURE STUDY}

After collecting data from millennial teachers in a secondary-school organization, a close evaluation of how to improve the relationship between millennials and non-millennials in a secondary-school organization is recommended. The data obtained from the current study indicated an opportunity for future research using the same or different methodology. A qualitative or quantitative study could be utilized to determine the impact of perceived challenges and opportunities for millennial teachers. The research can be expounded upon by soliciting non-millennial and millennial participants and comparing the qualitative data. The findings of the current study indicated results that allow for areas of opportunity for more discussion. The themes in the current study, such as the ability to build relationships and increased understanding of education and social connections, are possible foundations for future studies.

Various topics of study can be created from the findings of this study. The data in this study can create a further study on the impact millennial and non-millennial communication has on teacher retention. This study provides a foundation for different types of research to be conducted. This can be done using any of the various types of methodologies such as Phenomenological, Correlational or Causal comparative. As previously mentioned, a peer mentorship program may be beneficial for a school leader to implement. A future study may exist that determined whether or not a peer mentorship group or leadership program have an impact on student outcomes in a millennial teacher's classroom. These are the types of future studies that may occur based on the results of this study.

The participants provided evidence of misunderstanding between the millennial teachers and their leadership. Millennials expressed a strong desire for growth, while also embracing guidance from their peers and non-millennial leaders. The misunderstanding existed in the perception non-millennials have of young teachers. Future research can be conducted on the communication between millennials and their nonmillennial leaders, which could provide significant understanding of ways to create a healthy working environment. It is also important to know more about the types of employees leaders are seeking to hire. As current literature indicated, common characteristics of millennials suggest they are all about immediate gratification and selfishness. The information can be expounded upon and used to assist recruiting agencies and employers.

Experienced leaders, in the field of education, expressed the findings of this study may allow them to implement processes for millennial and non-millennials to interact in a manner that supports a positive and communicative culture. Leadership trainings and peer mentorship programs are examples of various ways educational leaders have stated they may utilize the data in this study.

The current study indicated that millennial teachers are driven and want to ensure they are working toward a direction that is supportive of professional growth. Further qualitative data can be obtained to delve into more reasons why millennials behave in a manner. If the behavior of millennials is mistaken as selfishness, and non-millennials treat millennials as though they are not ready for growth, it has the potential to create a culture of dismay. The current study indicated more research could be done on the motives of millennials. It is essential to discern the difference between a millennial behaving in a manner that is mitigating to a positive culture and behavior that exists based on a driven personality and desire to learn. This study also indicated the opportunity for further studies on the topic of millennials' perceptions, which may ultimately improve the relationship between millennials and non-millennials. 


\section{REFERENCES}

Barry, D. S., Marzouk, F., Chulak-Oglu, K., Bennett, D., Tierney, P., \& O'Keeffe, G. W. (2016). Anatomy education for the YouTube generation. Anatomical Sciences Education, 9(1), 90-96. doi:10.1002/ase. 1550

Baxter, P., \& Jack, S. (2008). Qualitative case study methodology: Study design and implementation for novice researchers. Qualitative Report, 13(4), 544-559.

Black, B. (2013, November). Youth lack life skills. Teen Ink, p. 24. Retrieved from http://www.teenink.com/opinion/school college/article/505367/Youth-Lack-Life-Skills/

Brady, R. P. (2010). Work readiness inventory. Indianapolis, IN: JIST Publishing.

Burbules, N. C. (2016). How we use and are used by social media in education. Educational Theory, 66(4), 551-565. doi:10.1111/edth.12188

Burbules, N. C. (2016). How we use and are used by social media in education. Educational Theory, 66(4), 551-565. doi:10.1111/edth.12188

Campione, W. A. (2014). The influence of supervisor race, gender, age, and cohort on millennials' job satisfaction. Journal of Business Diversity, 14(1), 18-34.

Carbaugh, B. (2016). Business passion: Frivolous fluff or essential to your future? Central Penn Business Journal, 32(15), 11.

Checkley, K. (2016). The open-ended question. Education Update, 58(5), 1-5.

Cramer, T. (2015). Millennials still mystify many. Econtent, 38(6), 3. Retrieved from http://www.econtentmag.com/Articles/Column/T.0/Millennials-Still-Mystify-Many-104905.htm

De Hauw, S., \& De Vos, A. (2010). Millennials' career perspective and psychological contract expectations: Does the recession lead to lowered expectations? Journal of Business and Psychology, 25(2), 293-302. doi:10.1007/s10869-010-9162-9

DeVaney, S. A. (2015). Understanding the Millennial Generation. Journal of Financial Service Professionals, 69(6), 11-14.

Dolph, D. A. (2016). To plan or not to plan, that is the question. Journal of Cases in Educational Leadership, 19(3), 100-109. doi:10.1177/1555458916657124

Ellis, A. (2016). How the Millennial Generation has redefined diversity. Public Relations Tactics, 23(6), 9.

Emeagwali, N. S. (2011). Millennials leading the charge for change. Techniques: Connecting Education and Careers, 86(5), 22-26.

Farrell, L., \& Hurt, A. C. (2014). Training the millennial generation: Implications for organizational climate. Journal of Organizational Learning and Leadership, 12(1), 47-60.

Farrell, L., \& Hurt, A. C. (2014). Training the millennial generation: Implications for organizational climate. Journal of Organizational Learning and Leadership, 12(1), 47-60.

Gafoor, K. A., \& Umer Farooque, T. K. (2010). Ways to improve lesson planning: A student teacher perspective. Paper presented at the International Seminar Cum Conference on Teacher Empowerment and Institutional Effectiveness, All India Association for Educational Research. Chitradurga, Karnataka, India. doi:10.13140/RG.2.2.27163.87840

Ganis, F. (2009). "Social Learning" Buzz Masks Deeper Dimensions: Mitigating the Confusion Surrounding "Social Learning". Online Submission.

Gass, H. (2015). For black millennials, black lives matter signals "weird moment". Christian Science Monitor.

Hall, A. (2016). Exploring the workplace communication preferences of millennials. Journal of Organizational Culture, Communications and Conflict, 1, 20, 35-44.

Hershatter, A., \& Epstein, M. (2010). Millennials and the world of work: An organization and management perspective. Journal of Business and Psychology, 25(2), 211-223. doi:10.1007/s10869-010-9160-y

Hickey, J. M. (2016). Toward a framework of culturally intelligent K-12 school leadership: A qualitative study of ten U.S.-based international school principals' described use of cultural intelligence in 
their interactions with students' families (Doctoral dissertation). Retrieved from Dissertation Abstracts International Section A, 76.

Hlavinka, S. L. (2014). The retention of Black and White millennial generation teachers working with diverse student populations. Dissertation Abstracts International: Section A, Humanities and Social Sciences, 74.

Hogan, A., Kyaw-Myint, S. M., Harris, D., \& Denronden, H. (2012). Workforce participation barriers for people with disability. International Journal of Disability Management, 7, 1-9. doi:10,1017/idm.2012.1

Hossain, F., \& Terwelp, E. (2015). Increasing employment opportunities for disadvantaged young adults. $M D R C, 44$.

Johnson, K. (2006). The Millennial teacher: Metaphors for a new generation. Pedagogy, 6(1), 7-24. doi:10.125/15314200-6-1-7

Jones-Goods, K. M. (2015). Culturally responsive leadership: A case study to explore stakeholders' perceptions of culturally responsive leadership in a K-12 public charter school in North Carolina (Doctoral dissertation). Retrieved from Dissertation Abstracts International Section A, 75.

Layton, D. L. (2016). Perceptions of Millennial teachers' commitment to teaching as a career (Doctoral dissertation). Retrieved from Dissertation Abstracts International Section A, 76.

Lerner, M. (2015). Demographic distress. Business Insurance, 49(26), 15. Retrieved from http://www.businessinsurance.com/article/20151213/NEWS06/312209993

Peebles, M. E. (2008). The trophy kids grow up: How the millennial generation is shaking up the workplace. In Harvard Business Review (p. 38). Harvard Business School Publication Corp.

Ragoonaden, K. O., Sivia, A., \& Baxan, V. (2015). Teaching for diversity in teacher education: Transformative frameworks. Canadian Journal for the Scholarship of Teaching and Learning, 6(3). doi:10.5206/cjsoti-rcacea.2015.3.6

Reuteman, R. (2015). Generation gaps. Entrepreneur, 43(3), 42-48.

Rodriguez, T. L., \& Hallman, H. L. (2013). Millennial teacher: A storied landscape of diversity in "New Times". Multicultural Perspectives, 15(2), 65-72. doi:10.1080/152109.60.2013.781344

Sago, B. (2010). The influence of social media message sources on millennial generation consumers. International Journal of Integrated Marketing Communications, 2(2), 7.

Severson, E. (2015). Employers can no longer stand on the sidelines. People and Strategy, 38(3), 11-12.

Smilansky, O. (2016). Generation Y: In control, content, and community-minded. CRM Magazine, 20(2), 20-24. Retrieved from http://www.destinationcrm.com/Articles/

ReadArticle.aspx?ArticleID=108824\&PageNum=1

Smith, D. J. (2012). Bridging the talent gap with a new generation. Grand Rapids Business Journal, 30(24), 9. Retrieved from http://www.grbj.com/articles/74206-bridging-the-talent-gap-with-anew-generation

Smith, S. D., \& Galbraith, Q. (2012). Motivating millennials: Improving practices in recruiting, retaining, and motivating younger library staff. Journal of Academic Librarianship, 38(3), 135-144. doi:10.1016/j.acalib.2012.02.008

Soenens, B., Wuyts, D., Vansteenkiste, M., Mageau, G. A., \& Brenning, K. (2015). Raising trophy kids: The role of mothers' contingent self-esteem in maternal promotion of extrinsic goals. Journal of Adolescence, 4(2), 40-49. doi:10.1016/j.adolescence.2015.04.001

Twenge, J. M. (2010). A review of the empirical evidence of generational differences in work attitudes. Journal of Business and Psychology, 25, 201-210. doi:10.1007/s10869-010-9165-6

Warnell, J. M. (2012). Giving voice to values: Engaging Millennials and managing multigenerational cultures. In W. I. Sauser \& R. R. Sims (Eds.), Managing human resources for the millennial generation (pp. 117-137). Charlotte, NC: IAP Information Age Publishing. 